\title{
CONSIDERAÇÕES SOBRE ERROS ORTOGRÁFICOS ENVOLVENDO OS DITONGOS VARIÁVEIS
}

\author{
CONSIDERATIONS ON ORTHOGRAPHIC ERRORS \\ INVOLVING VARIABLE DIPHTHONGS
}

\author{
Marco Antônio Adamoli \\ Instituto Federal Sul-rio-grandense, Pelotas, Rio Grande do Sul, Brasil \\ marcoaadamoli@gmail.com
}

Resumo: O presente artigo focaliza o erro ortográfico referente à grafia dos ditongos variáveis do Português Brasileiro "ai", "ei" e "ou", em textos produzidos por crianças em fase de alfabetização, nos quais são constatados casos tanto envolvendo inserção de semivogal (caichoeira, goustou), quanto apagamento dessa estrutura (fejão, caxa). Os trabalhos que se ocupam desse assunto revelaram duas tendências para o surgimento de erros envolvendo essa classe de ditongo, a saber, a influência da oralidade e do próprio processo de escolarização. Ainda que incorretos em termos gramaticais, tais desvios indiciam a construção de hipóteses da criança que, muitas vezes, toma como base para sua escrita aquilo que já aprendeu sobre estruturas linguísticas da língua.

Palavras-chave: Alfabetização; Aquisição da Escrita; Grafia dos Ditongos Variáveis

Abstract: The present paper aims to analyze misspelling related to the spelling of the variable diphthongs in Brazilian Portuguese "ai", "ei" and "ou" in texts produced by children in literacy phase, in which are found cases involving the insertion of a semivowel (caichoeira, goustou), or even the deletion of this structure $(f \boldsymbol{e} j \tilde{a} o, c \boldsymbol{a} x a)$. Previous papers related two possible tendencies for the emergence of mistakes involving this class of diphthong, such as: the influence of speaking and of the schooling itself. Even though these misspellings are considered to be incorrect on the grammar terms, such evidence indicates the construction of hypotheses by children who, several times, base themselves on what they have already learnt about the linguistic structure of their language.

Keywords: Literacy; Acquisition of Writing; Spelling of Variable Diphthongs 


\section{INTRODUÇÃO}

Neste artigo $^{1}$, são apresentados textos redigidos por crianças em fase de alfabetização dos quais são tomados alguns erros ortográficos com a finalidade de evidenciarem-se relações entre o sistema sonoro da língua e aspectos da ortografia do Português. Precisamente, o texto discute o surgimento de grafias não convencionais detectadas nas tentativas de escrita dos ditongos variáveis "ai", "ei" e "ou". Essas três estruturas suscitam frequentemente dúvidas aos aprendizes de escrita, levando-os a apagarem os grafemas "i" e " $u$ " que constituem as semivogais desses ditongos (caxa, fejão, otro), ou a acrescentarem tais grafemas em palavras que não apresentam ortograficamente esses grupos vocálicos (caichoeira, morreiram, boutou).

$\mathrm{O}$ artigo pretende mostrar que, mesmo sendo considerados incorretos em termos gramaticais, erros ortográficos dessa natureza revelam a construção gradual de hipóteses das crianças que, muitas vezes, tomam como base conhecimentos linguísticos já apreendidos em decorrência da exposição à língua, dos quais extraem subsídios fonético-fonológicos, morfológicos, sintáticos, discursivos, textuais, entre outros, empregando-os, não raro, como suporte enquanto estão a aprender a escrita nos anos iniciais da escolarização. No que diz respeito especificamente ao componente fonético-fonológico da língua, a literatura apresenta diversos estudos que evidenciam uma relação mais estreita entre aspectos da aquisição da escrita - notadamente o erro ortográfico - e o conhecimento internalizado da criança sobre esse componente sonoro (ABAURRE, 1987, 1999, 2011; MIRANDA, 2008, 2010, 2012, 2014; CUNHA, 2004, 2010; ROMBALDI, 2011; ADAMOLI, 2006, 2012; ADAMOLI e MIRANDA, 2009, 2018; entre outros).

Pesquisas voltadas à descrição e à compreensão da grafia dos ditongos variáveis indicaram a prevalência de duas tendências principais para o surgimento de erros ortográficos, a saber, a influência da oralidade e do próprio processo de escolarização. Assim, conhecendose as razões para o surgimento desses erros, pensa-se que, para além de uma discussão teórica, a explanação do tema possa contribuir para a compreensão de fenômenos linguísticos por parte dos envolvidos no ensino da escrita, especialmente os professores alfabetizadores, de maneira a levá-los a uma atuação mais científica para a resolução de problemas ortográficos.

\section{OS DITONGOS VARIÁVEIS DO PORTUGUÊS}

As gramáticas normativas costumam definir os ditongos do Português Brasileiro como um grupo vocálico constituído por uma vogal seguida de uma semivogal ou vice-versa, na mesma sílaba, podendo ser crescentes ou decrescentes, orais ou nasais. A posição da semivogal ( $i$ ou $u$ ) no grupo vocálico, se antes ou depois da vogal, será determinante para a classificação do ditongo. Na palavra "leite", por exemplo, o encontro vocálico "ei" termina por uma vogal com menor saliência fônica, propiciando o surgimento de um ditongo decrescente; já em "glória", a semivogal antecede a vogal, razão por que a sequência "ia" recebe a classificação de ditongo crescente ${ }^{2}$. Neste estudo, serão focalizados apenas erros ortográficos envolvendo os ditongos decrescentes.

\footnotetext{
${ }^{1}$ Texto apresentado no Painel de Pesquisas do II Seminário Integrador Obeduc-Pacto: Formação de Professores, Leitura e Escrita no Ciclo de Alfabetização.

${ }^{2} \mathrm{Na}$ literatura da área, há uma discussão iniciada por Câmara Jr. (1977) sobre a existência de ditongos crescentes no Português. Bisol (1989) também advoga em favor da não existência dessa classe de ditongos na língua. Essa discussão, no entanto, foge aos propósitos deste artigo, razão por que não será aqui abordada. Por razões didáticas, será mantida a classificação da Nomenclatura Gramatical Brasileira (NGB).
} 
O Português possui 11 ditongos decrescentes, conforme descrição de Câmara Jr. (1977), como mostra a Figura 1:

Figura 1 - Ditongos decrescentes (CÂMARA JR., 1977)

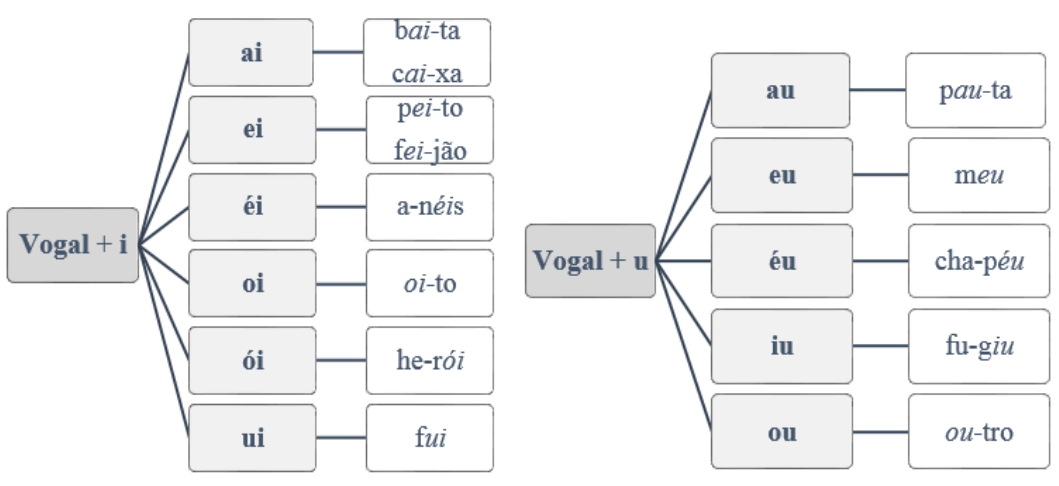

Fonte: elaborado pelo autor.

Desse grupo, três ditongos - ai, ei e ou - podem sofrer processo de cancelamento da semivogal tanto na fala quanto na escrita. Esse fenômeno, também chamado de monotongação, não gera mudança ao significado da palavra, por exemplo, em "caixa $\sim$ caxa", "ameixa amexa" e "couve cove". Esses três ditongos são chamados de variáveis ou fonéticos (BISOL, 1989, 1994, 2012); invariáveis são os que não sofrem tal processo, mantendo-se, portanto, íntegras vogal e semivogal, como em "pauta", mas não "pata". A diferença de comportamento entre essas duas classes de ditongo pode ser vista na Figura 2 a seguir:

Figura 2 - Diferença entre ditongos variáveis e invariáveis

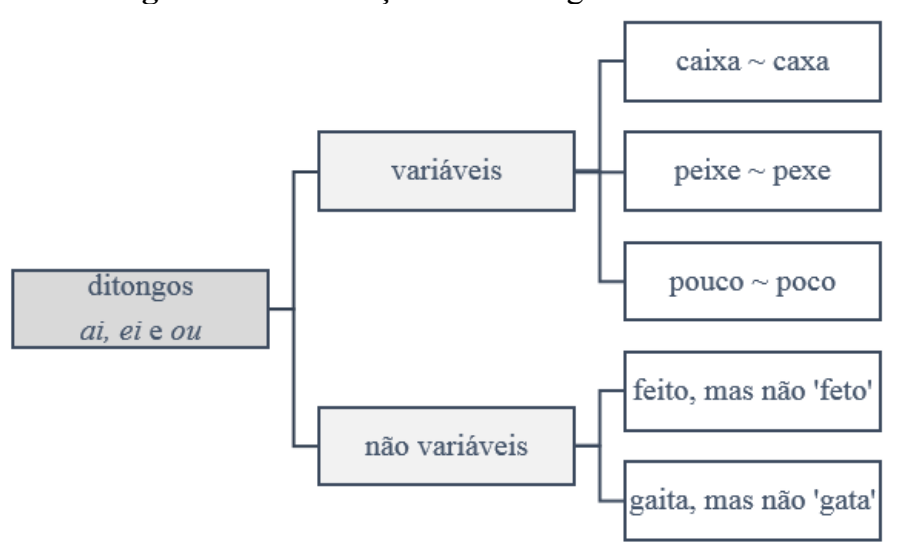

Fonte: elaborado pelo autor.

O ditongo "ai" é o que pode perder a semivogal, tanto na fala quanto na escrita, diante de dois contextos fonológicos apenas, [S] e [3], sendo este último observado em raras palavras da língua, como no vocábulo de origem indígena "saijé". Por sua vez, o ditongo "ei" apresenta um maior número de ambientes ${ }^{3}$ em que se pode verificar a supressão da semivogal, com destaque a três principais, [S], [3] e [ $\mathrm{c}$, o que explica o maior percentual de erros ortográficos envolvendo esse grupo vocálico em textos infantis, conforme apontou Adamoli (2006), especialmente diante de [r]. Diferentemente do que ocorre com esses dois ditongos, a supressão da semivogal de "ou" é de caráter geral, sendo observada diante de todos os contextos

\footnotetext{
${ }^{3}$ A supressão da semivogal [j] também pode ser observada na fala diante de outras consoantes, como: [m], em [kej'mow ke'mow]; [n], em ['trejno 'treno]; [g], em [mã'tejge mã'tege]; e [K], em [ko'Kejte ko'Kete].
} 
consonantais e gerando, consequentemente, altos índices de monotongação na fala dos brasileiros em todas as regiões do país. $\mathrm{Na}$ escrita infantil, o comportamento das crianças em relação a esse ditongo não é diferente, sendo aquele apontado por Adamoli (2006) como o que mais dificuldades traz aos aprendizes de escrita.

\section{METODOLOGIA}

Os dados que servem de base para esta discussão foram extraídos de textos produzidos por crianças em fase de alfabetização em dois momentos distintos, como segue:

- Textos coletados de maneira espontânea, pertencentes a crianças que cursavam, à época das coletas, as duas primeiras séries do ensino fundamental de uma escola pública e outra particular da cidade de Pelotas/RS. As crianças foram estimuladas a escrever a partir de diferentes atividades, geralmente leituras de contos de fadas e pequenas histórias em quadrinhos sem diálogos, livres de qualquer interferência de professores e aplicadores das tarefas no momento das escritas. Aproximadamente 950 produções textuais compunham o corpus da pesquisa, totalizando 10 coletas de textos, em cada uma das séries.

- Textos produzidos ao longo de dois anos consecutivos, com uma coleta ao final do primeiro ano e duas ao final do segundo ano. A pesquisa, de caráter longitudinal, investigou 15 alunos em seus dois primeiros anos de escolarização em uma escola pública da cidade de Pelotas/RS. As crianças eram estimuladas a escrever a partir de instrumentos específicos criados para a pesquisa, a saber, nomeação de um conjunto aproximado de 30 figuras aplicado na $1^{\mathrm{a}}$ e $2^{\mathrm{a}}$ coletas (FIGURA 3) ou pequenas sequências narrativas usadas na $3^{\mathrm{a}}$ coleta (FIGURA 4), nas quais havia imagens cujos nomes apresentam os ditongos variáveis aqui em foco.

Figura 3 - Exemplo de instrumento de coleta de dados

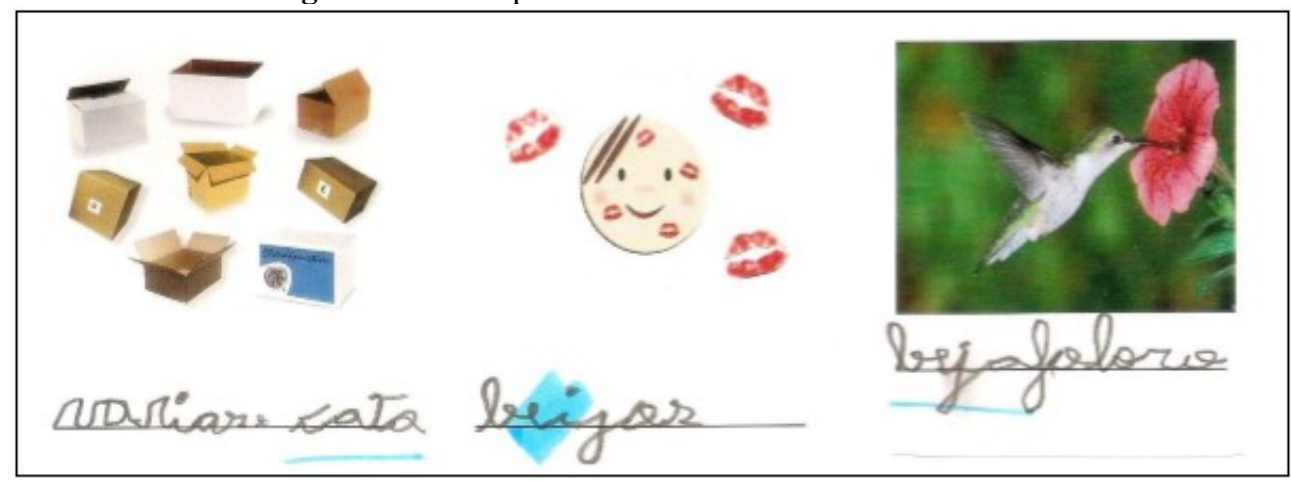

Fonte: GEALE. 
Figura 4 - Exemplo de instrumento de coleta de dados

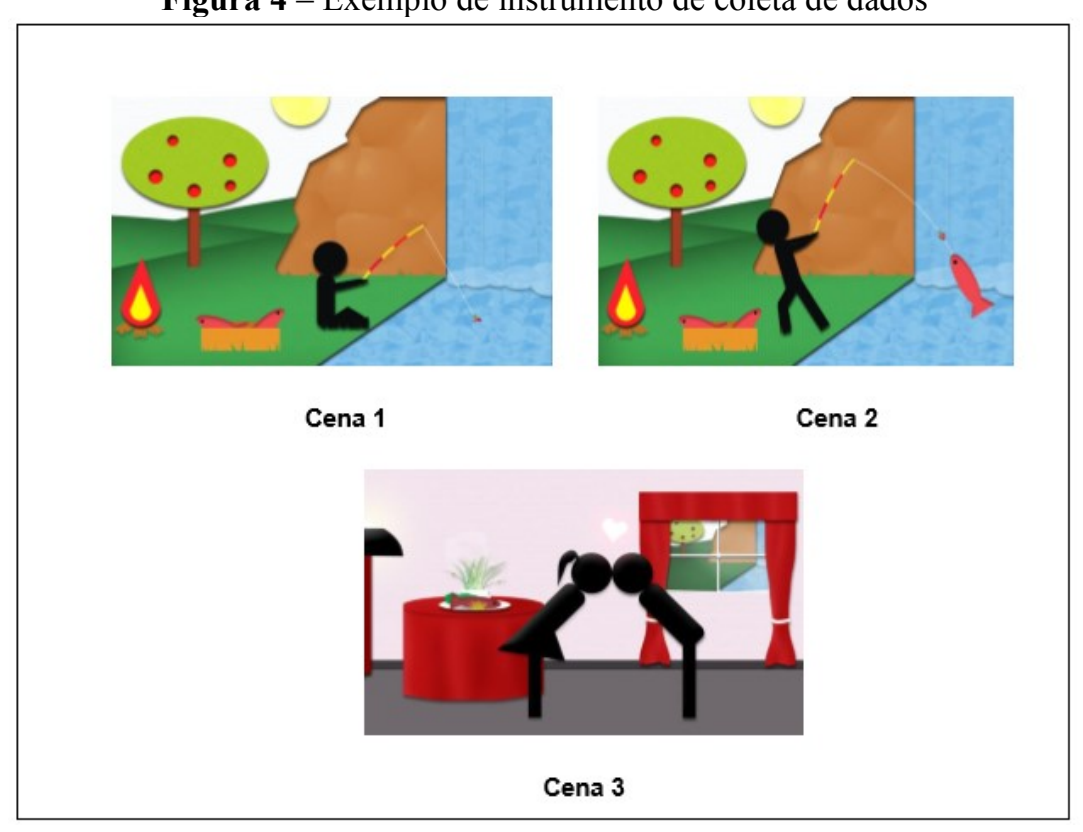

Fonte: GEALE.

\section{ERROS ORTOGRÁFICOS NA ESCRITA DOS DITONGOS VARIÁVEIS: MOTIVAÇÕES}

Em Explorações sobre o desenvolvimento da competência em ortografia em Português, Carraher (1990) menciona que os desvios ortográficos observados em textos produzidos por crianças pertencentes ao ciclo de alfabetização podem, não raro, apresentar uma motivação e, como tal, são passíveis de explicação. As motivações apresentadas a seguir para a grafia dos ditongos variáveis indiciam não só as dificuldades por que passam os pequenos aprendizes de escrita diante da tarefa de escrever tais estruturas linguísticas, mas também as soluções oferecidas por eles para escrevê-las.

Essas soluções podem funcionar como pistas para professores, especialmente os alfabetizadores, intervirem por meio de ações didáticas diferenciadas que os levem, sobretudo, à reflexão sobre essas estruturas de nossa língua. Com esse objetivo, apresentam-se, na sequência, duas principais motivações para o surgimento desse tipo de erro com base em resultados de pesquisas (ADAMOLI, 2006, 2012; ADAMOLI; MIRANDA, 2018) que trataram da grafia dos ditongos variáveis "ai", "ei" e "ou" do português brasileiro.

\subsection{ERROS ORTOGRÁFICOS MOTIVADOS PELA ORALIDADE}

Erros motivados foneticamente são assim chamados por serem resultantes de alguma interferência da oralidade sobre a escrita, imprimindo nesta o conhecimento que o falante da língua já tem internalizado. Zorzi (1998) classifica esse tipo de erro como a maneira que as crianças possuem em apoiar-se no modo de falar para decidir o modo de escrever. São, portanto, erros em que há uma clara tentativa de a criança estabelecer relação mais direta entre os elementos sonoros e os grafemas que representam as unidades sonoras da língua. 
Muitos estudos sobre aquisição da escrita, entre os quais os desenvolvidos no âmbito do GEALE ${ }^{4}$, já revelaram a presença desse tipo de motivação na escrita inicial de crianças, em cujos textos aparecem formas ortográficas como "pega" (pegar), "minino" (menino), "lobu" (lobo). Abaurre (1999) diz que a modalidade escrita possui autonomia em relação à modalidade oral, o que não impede de, em certas circunstâncias, haver uma interação entre fatos da oralidade e as formas que assume a escrita (ABAURRE, 1999, p. 174). No entendimento da autora, essa hipótese supõe a possibilidade de "vazamentos" da oralidade para a escrita, algo que foge às intenções e ao controle das crianças.

Tal possibilidade pode ser considerada para justificar um número expressivo de erros ortográficos que se faz presente nas etapas iniciais da alfabetização. Um deles envolve os ditongos variáveis, cujas semivogais são frequentemente apagadas pelas crianças nesse período, especialmente no primeiro ano, independentemente de os estudantes pertencerem à escola pública ou particular. Dada a grande similaridade com as manifestações orais dos ditongos fonéticos, os erros de escrita apontados nos textos infantis podem ser atribuídos, nesse primeiro momento da aprendizagem escolar, à decorrência de "vazamentos" da oralidade. Foi o que mostrou o estudo de Adamoli (2006) sobre a grafia desses três ditongos em textos produzidos espontaneamente por crianças pertencentes aos dois primeiros anos do ensino fundamental.

Para o autor, os contextos favorecedores da perda da semivogal na fala também constituíram os principais ambientes frente os quais os grafemas "i" e " $u$ " deixaram de ser grafados, confirmando o que têm apontado os estudos variacionistas acerca da supressão dessas duas semivogais na fala. A grande maioria dos textos redigidos no primeiro ano do ensino fundamental apontou a preferência dos aprendizes pelas formas monotongadas, isto é, apenas a vogal plena se fez presente nos textos infantis, revelando grande similaridade entre o fonema e o grafema que o representam, como pode ser comprovado nas Figuras 5, 6 e 7:

Figura 5 - Exemplos de escrita infantil
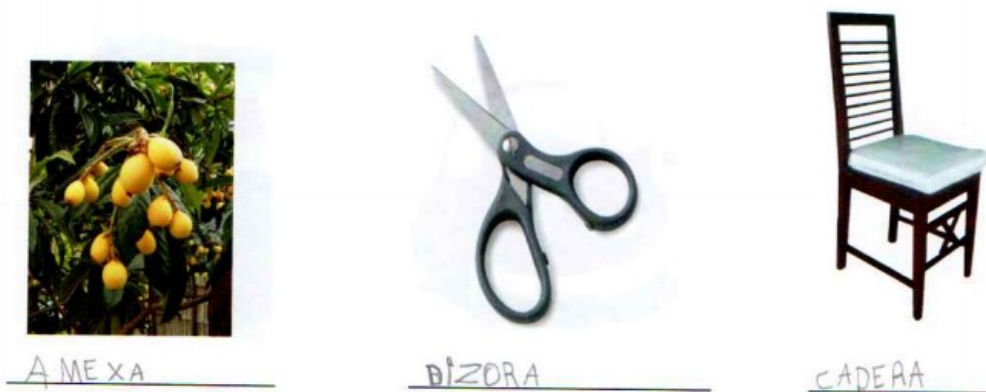

Fonte: GEALE.

\footnotetext{
${ }^{4}$ O Grupo de Estudos sobre Aquisição da Linguagem Escrita (GEALE) desenvolve pesquisas sobre erros ortográficos produzidos por crianças das séries/anos iniciais, sendo coordenado pela Prof ${ }^{\mathrm{a}}$. Dr ${ }^{\mathrm{a}}$. Ana Ruth Moresco Miranda (FaE/UFPel).
} 
Figura 6 - Produção escrita infantil

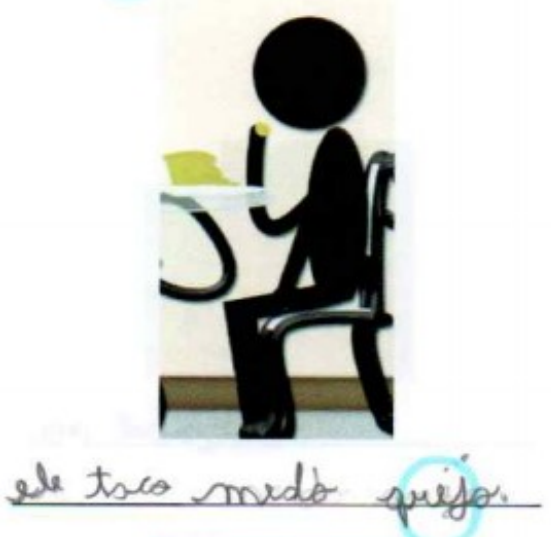

Fonte: GEALE.

Figura 7 - Produção escrita infantil

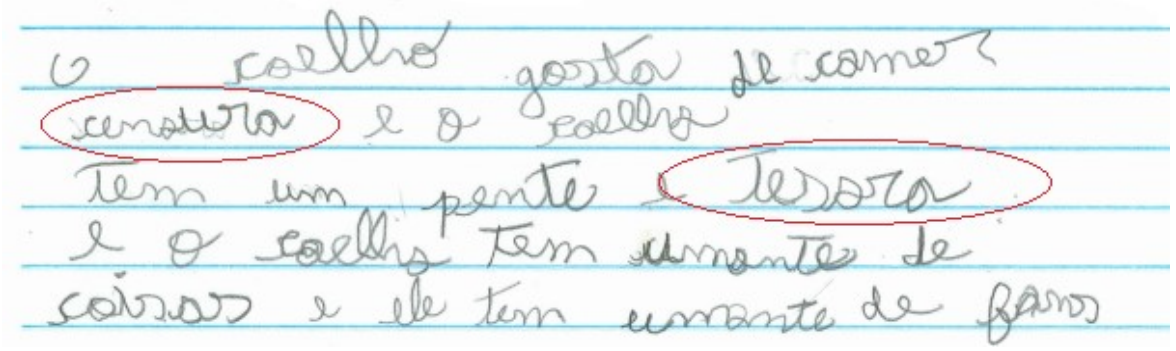

Fonte: GEALE.

As pesquisas em aquisição da escrita (ADAMOLI, 2006, 2012; HORA, 2007; HORA; RIBEIRO, 2006; TASCA, 2002, entre outras) têm revelado uma frequência relativamente alta da redução desses grupos vocálicos frente aos mesmos contextos fonológicos em que ocorre o apagamento das semivogais na fala. Nas Figuras 5 e 6, verifica-se a supressão da semivogal "i" nas palavras "amexa", "cadera" e "quejo", sendo esses os três principais contextos fonológicos mais frequentes para a observância do fenômeno em estudo, segundo pesquisas variacionistas (AMARAL, 2005; ARAÚJO, 2000; CABREIRA, 1996). Na Figura 7, chama a atenção a existência de duas palavras que requerem ortograficamente o ditongo "ou" (cenoura e tesoura), mas somente em uma delas, em "cenoura", a criança grafa esse ditongo conforme determina a norma, revelando suas incertezas quanto à escrita dessa estrutura nesse momento da alfabetização.

Apesar de serem frequentes esses erros, a criança irá aprender a forma correta de grafar os ditongos variáveis no decorrer dos primeiros anos do ciclo de alfabetização, muito por conta das atividades de leitura e de escrita oferecidas pela escolar. Tais atividades a ajudarão a memorizar palavras em que se fazem presentes esses grupos vocálicos, contrastando-as com aquelas em que estes não aparecem - como em "bandeja", faxina" e boca", e não "bandeija", "faixina" e "bouca" - e também a incorporar esses vocábulos ao seu léxico mental.

Em estudo sobre a aquisição oral e ortográfica dos ditongos variáveis "ai" e "ei", Adamoli (2012) atribuiu ao próprio processo de aprendizagem da leitura e da escrita o aumento das formas convencionais de se grafarem esses dois ditongos. O acompanhamento ao longo de dois anos consecutivos em uma turma de alfabetizandos e a comparação entre as grafias observadas ao final do primeiro e do segundo escolar demonstraram que o grupo investigado havia compreendido, ao final do segundo ano escolar, as diferenças entre as modalidades falada e escrita da língua no que toca a esse aspecto ortográfico. Os resultados mostraram que as 
crianças compreenderam que devem representar ortograficamente com a vogal "i" segmentos que, em geral, nem sempre são produzidos na fala.

As formas corretas de grafia dessa classe de ditongos parecem estabilizar-se, como se disse, no final do segundo ano escolar, justamente quando a escolarização se encontra mais adiantada entre os aprendizes e quando estes se encontram mais desenvolvidos cognitivamente. Isso permite concluir que o processo de alfabetização é, portanto, um momento em que se verifica uma construção progressiva do conhecimento ortográfico por parte das crianças. Em assim sendo, o tempo em que os aprendizes de escrita ficam expostos à aprendizagem parece ser determinante para tornar mínima a variação ortográfica verificada nas escritas infantis como decorrentes da oralidade.

\subsection{ERROS MOTIVADOS PELO PROCESSO DE ALFABETIZAÇÃO}

Outra motivação para o surgimento de erros ortográficos abrangendo os ditongos variáveis envolve casos de supergeneralização, fenômeno que, para Menn e Stoel-Gammon (1997), marca a verdadeira aprendizagem de uma regra, uma vez que demonstra que as crianças ainda não conseguiram atentar para as sub-regularidades do sistema de escrita, ao empregarem uma regra a um contexto em que ela não se aplicaria. Casos de supergeneralização podem ser evidenciados quando os aprendizes de escrita grafam "amanhecel" (amanheceu) e "vio" (viu), por exemplo. Nessas situações, a criança generaliza quando percebe que a vogal "u", em posição átona e de final de sílaba, é frequentemente representada por "o" ou "l", grafando "viu" como "vio" ou "vil", sem atentar para o fato de que o morfema de $3^{a}$ pessoa do singular, em verbos no pretérito perfeito do indicativo, é convencionalmente escrito com "u" (comeu, partiu).

Nos textos infantis analisados, foram observados casos em que as crianças inseriram graficamente as semivogais "i" e "u" após a vogal em palavras que não apresentam ortograficamente os ditongos "ei" e "ou". Mesmo sendo reduzido o número de casos de inserção dessas semivogais, quando comparado ao de supressão, o fenômeno é interessante de ser analisado, pois igualmente revela o conhecimento adquirido pela criança em suas experiências com a escrita relativamente à presença de ditongos na sua língua, como mostram os casos em 4.2.1 e 4.2.2.

\subsubsection{Inserção da semivogal "i”}

Os dados analisados por Adamoli $(2006,2012)$ mostraram a existência de um tipo de erro em que as crianças inseriram a semivogal "i" em palavras nas quais não se faz presente o ditongo. Em etapas mais avançadas do ciclo de alfabetização e letramento - especialmente no segundo ano escolar -, por meio de tentativas de correção dos erros de transcrição da oralidade, as crianças começam a atentar para diferenças existentes entre fala e escrita, o que as leva, muitas vezes, a cometer outros tipos de grafias não convencionais, abrindo caminho para o surgimento de formas como "feichar" (fechar), "caichoeira" (cachoeira), "morreiram" (morreram), entre outras.

As ocorrências de erros ortográficos dessa natureza são bastante reduzidas em comparação às discutidas anteriormente. Convém ressaltar, no entanto, que essas inserções não anulam o entendimento de se considerar esse tipo de desvio como um indício de que os alunos estejam passando por processos que indicam uma evolução na escrita das formas ortográficas dos ditongos. As Figuras 8, 9 e 10 a seguir trazem exemplos do que se está a discutir. 
Figura 8 - Exemplo de escrita infantil

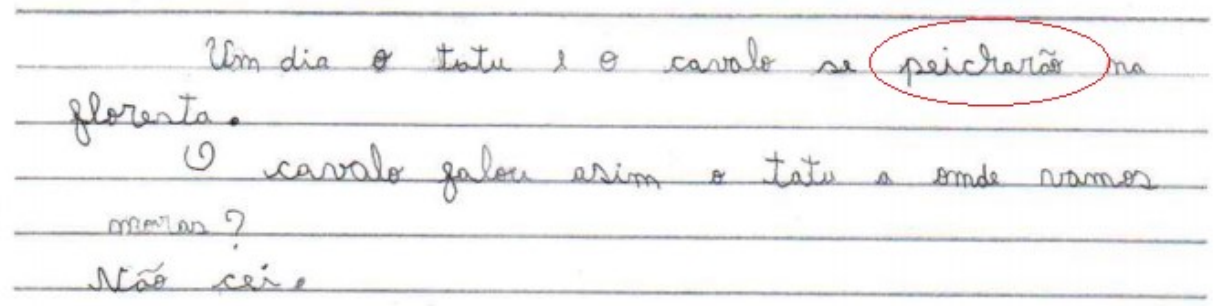

Fonte: GEALE.

Figura 9 - Exemplo de escrita infantil

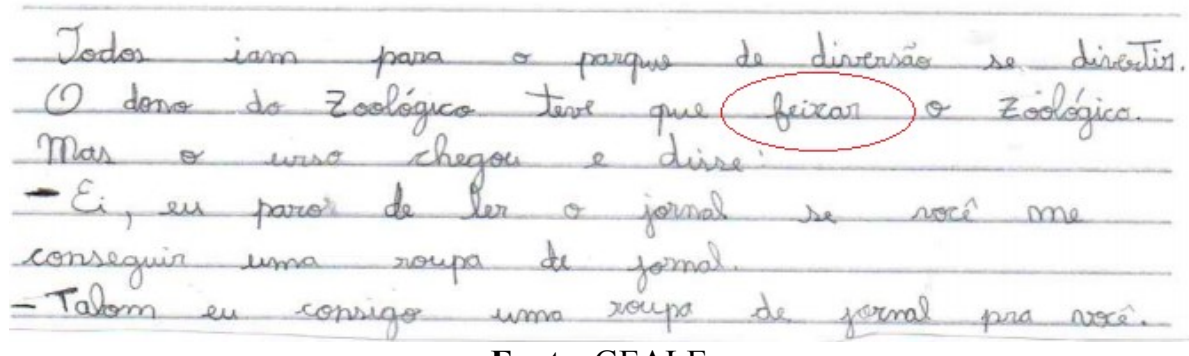

Fonte: GEALE.

Figura 10 - Exemplo de escrita infantil

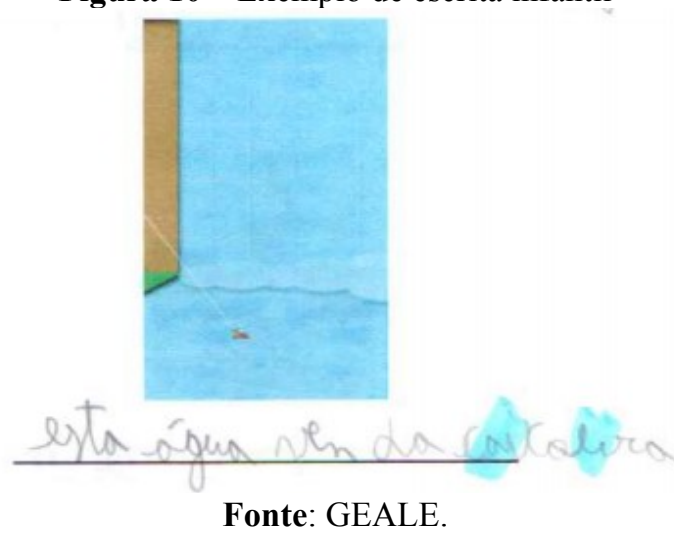

Os textos mostram que as crianças grafaram os ditongos "ai" e "ei" diante dos mesmos contextos fonológicos em que se verifica, na fala ou na escrita, a supressão da semivogal. Como citado em outros momentos (ADAMOLI, 2006, 2012; ADAMOLI; MIRANDA, 2009, 2018), dados singulares como esses corroboram a hipótese de que os contextos fonológicos frente aos quais são produzidos, tanto oral quanto graficamente, já são reconhecidos por crianças pequenas. Interessante chamar a atenção para o fato de que esses textos foram produzidos por crianças que, à época, cursavam a $2^{\mathrm{a}}$ série e o segundo ano do ensino fundamental, fornecendo indícios que apontam para o reconhecimento do contexto seguinte como propício tanto para apagar quanto para inserir a semivogal " $\mathrm{i}$ ". Prova disso advém do fato de que, no conjunto de textos que deram base à discussão aqui proposta, foram observados casos de acréscimo da semivogal "i" diante apenas dos três principais ambientes fonológicos que favorecem a monotongação, a saber, as consoantes / $, 3, \mathrm{r} /$, as quais, segundo Bisol $(1989,1994,2012){ }^{5}$ propiciam o surgimento da semivogal [j].

\footnotetext{
${ }^{5}$ A autora, com base nos pressupostos da teoria Autossegmental, defende que tais consoantes possuem status de segmentos complexos, o que implica a existência de um nó vocálico em sua constituição. Esse nó vocálico, por meio de um processo denominado de espraiamento, seria o responsável pelo surgimento do segmento vocálico
} 
Além dessa explicação que permite compreender por que as inserções ocorrem antes dos contextos de $/ \int, 3, \mathrm{f} /$ - sons que representam, respectivamente, os grafemas " $\mathrm{x} / \mathrm{ch}$ ", " $\mathrm{g} / \mathrm{j}$ " e " $r$ " -, pode-se, da mesma forma, incluir o argumento de que conhecimentos adquiridos por meio das práticas de letramento também podem estar aí atuando para a produção de erros como recém apresentados. Muito possivelmente as crianças, no segundo ou terceiro ano escolar, já devem ter aprendido a regra segundo a qual o ditongo não é pronunciado, mas escrito em contextos tais, aplicando-a em contextos semelhantes, mas indevidos ortograficamente.

Esse tipo de erro se mostra especialmente importante por indicar que, diante dos percentuais de monotongação na escrita e da similaridade entre os contextos fonológicos, o conhecimento fonético-fonológico infantil é acionado como base para a escrita de palavras que apresentam tais sequências vocálicas, quando as crianças começam a se apropriar das convenções ortográficas estabelecidas pelo processo escolar.

\subsubsection{Inserção da semivogal " $u$ "}

Também é comum crianças em fase de aprendizagem da escrita inserirem indevidamente a semivogal " $u$ " em palavras nas quais não se registra ortograficamente o ditongo "ou", como mostram as Figuras 11 e 12:

Figura 11 - Exemplo de escrita infantil

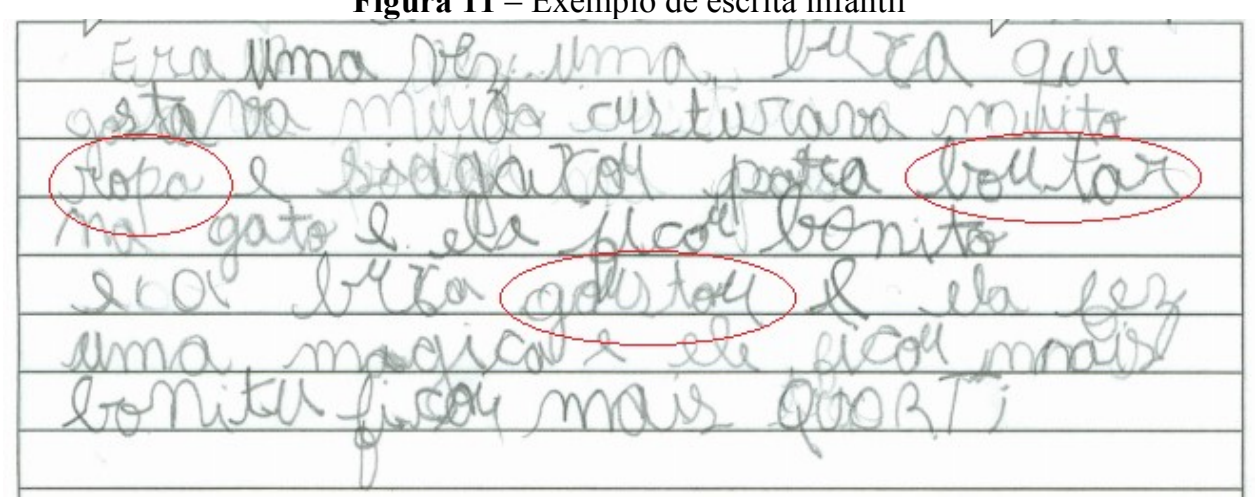

Fonte: GEALE.

Figura 12 - Exemplo de escrita infantil

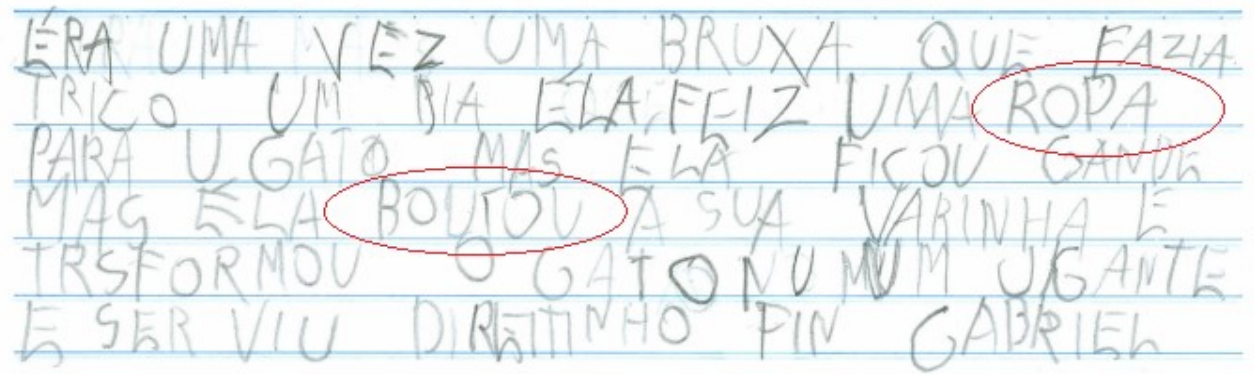

Fonte: GEALE.

O tratamento diferenciado quanto ao ditongo "ou" desperta a atenção uma vez mais justamente por revelar a incerteza, por parte dos aprendizes, quanto ao emprego da semivogal "u". No primeiro texto, a criança apaga essa estrutura em uma palavra cuja ortografia prevê

epentético [j]. Há, porém, divergência na literatura da área quanto à complexidade desses segmentos (CLEMENTS \& HUME, 1995). 
esse ditongo (ropa), mas em seguida a acrescenta em vocábulos que não apresentam esse grafema (boutar e goustou). No segundo texto, o movimento feito pela criança não é diferente daquele observado anteriormente, ou seja, ela não grafa a semivogal em "ropa", mas o faz em "boutou" (botou).

Erros como esses parecem indicar que a inserção em práticas de letramento, a partir das atividades de leitura e escrita propostas em casa e principalmente na escola, pode levar a criança a generalizar a regra de que, se qualquer 'ou' pode passar a 'o' na fala, consequentemente, qualquer 'o' pode passar a 'ou' na escrita. A descoberta de tal relação a leva, nesse período em que se encontra, a cometer erros ortográficos como os aqui apresentados, como "boutar", "goustou" e "boutou". Nesse tipo específico de situação, o português não apresenta regra que mostre aos usuários da língua quando exatamente têm de empregar o ditongo "ou". Sendo assim, a aprendizagem da forma ortográfica dessa estrutura ocorrerá, sobretudo, pela memorização de itens lexicais nos quais "ou" se faz presente e pela sua inclusão ao léxico mental da criança.

É importante referir que já são observados casos de supergeneralização no primeiro ano escolar, mas uma maior quantidade de erros desse tipo é constatada no segundo ano, quando a criança, de posse de mais conhecimentos sobre regras ortográficas do português, começa a compreender que fala e escrita são processos distintos e que, portanto, cada uma dessas modalidades apresenta peculiaridades.

As variações envolvendo o ditongo "ou" demonstram a descoberta pela criança de relações e de correspondências com estruturas que possuem natureza semelhante. Casos como os discutidos neste trabalho indicam, na verdade, uma criança que parece reorganizar seu pensamento frente a estruturas linguísticas a ela disponíveis. Nessa caminhada, entretanto, surgem alguns percalços - os erros ortográficos - que, de acordo com a concepção aqui assumida, são evidências claras de que algo interno está, gradualmente, sendo reestruturado.

\section{CONLUSÃO}

Como procurou mostrar este trabalho, os dados ortográficos relativos às tentativas de grafias dos ditongos variáveis, por meio de apagamentos ou de inserções de semivogais, em textos de crianças em processo de alfabetização, parecem confirmar a hipótese de que elas refletem e, mais do que isso, atuam sobre suas escritas, fazendo muitas vezes escolhas ortográficas plausíveis, embora em alguns momentos em descordo com o previsto pelo sistema de escrita padrão. Ao utilizarem-se de estratégias para grafarem tais estruturas silábicas, especialmente aquelas observadas nos casos de supergeneralização, as crianças demonstram sua competência linguística na tentativa de apropriação das regras ortográficas do português.

Os dados ortográficos que serviram para a discussão apresentada anteriormente puderam comprovar que o processo de alfabetização é realmente um momento em que se verifica uma construção progressiva do conhecimento ortográfico por parte das crianças. Ainda que incorretas como se disse, tais escolhas parecem lançar luz sobre as concepções de linguagem e de escrita que a grande maioria dos aprendizes possui nesse importante momento da aprendizagem. $\mathrm{O}$ tempo, pois, em que estes ficam expostos na escola à aprendizagem parece ser determinante para tornar mínima a variação ortográfica verificada nas escritas infantis, na qual entram em jogo aspectos da oralidade e também do próprio processo de alfabetização.

Conhecer, portanto, a natureza dos erros infantis, sejam estes relacionados aos ditongos variáveis ou a qualquer outra estrutura linguística do português, permitirá aos profissionais envolvidos no processo de alfabetização um exame mais detalhado dos erros ortográficos e, consequentemente, a definição de propostas de ensino para auxiliar as crianças, como diz 
Soares (2017, p. 328), "no desenvolvimento de conhecimentos e habilidades que as conduzem às competências de leitura e de escrita de palavras, à alfabetização".

\section{REFERÊNCIAS}

ABAURRE, Maria Bernadete Marques. Horizontes e limites de um programa de investigação em aquisição da escrita. In: LAMPRECHT, Regina. (org.). Aquisição da linguagem: questões e análises. Porto Alegre: EDIPUCRS, 1999.

ABAURRE, Maria Bernadete Marques. A Relação entre escrita espontânea e representações linguísticas subjacentes. Verba Volant, v. 2, $\mathrm{n}^{\mathrm{o}}$ 1. Pelotas: Editora e Gráfica Universitária da UFPel, 2011.

ABAURRE, Maria Bernadete Marques. O que revelam os textos espontâneos sobre a representação que faz a criança do objeto escrito? Anais do GEL, 1987, p. 135-142.

ADAMOLI, Marco Antônio; MIRANDA, Ana Ruth Moresco. Dados de aquisição da fala e da escrita e sua contribuição à discussão dos ditongos fonéticos [aj] e [ej] do PB. Revista Linguagem \& Ensino, Pelotas, v. 21, 2018, p. 73-118.

ADAMOLI, Marco Antônio. Um estudo sobre o estatuto fonológico dos ditongos variáveis [aj] e [ej] do PB a partir de dados orais e ortográficos produzidos por crianças de séries iniciais. 2012. 196 p. Tese (Doutorado em Educação) - Faculdade de Educação, Universidade Federal de Pelotas, 2012.

ADAMOLI, Marco Antônio. Aquisição dos ditongos orais mediais na escrita infantil: uma discussão entre ortografia e fonologia. 2006. 121 p. Dissertação (Mestrado em Educação) Faculdade de Educação, Universidade Federal de Pelotas, 2006.

ADAMOLI, Marco Antônio; MIRANDA, Ana Ruth Moresco. Do conhecimento fonológico ao conhecimento ortográfico: as diferentes grafias dos ditongos orais mediais 'ai' e 'ei' em textos de escrita inicial. In: BISOL Leda.; BRESCANCINI, Cláudia. (Orgs.) Cadernos de Pesquisa em Linguística. Porto Alegre, v. 4, n. 1, 2009, p. 232-245.

AMARAL, Marisa Porto do. Ditongos variáveis no sul do Brasil. Letras de Hoje. Porto Alegre, v. 40, n 3, 2005, p. 101-116.

ARAÚJO, Maria Francisca Ribeiro de. Considerações sobre a monotongação do ditongo decrescente [ej] no dialeto de Caxias (MA). Revista de Letras. Campinas, v. 19, 2000.

BISOL, Leda. Ditongos derivados: um adendo. In: LEE, Seung Hwa (Org.). Vogais além de Belo Horizonte. Belo Horizonte: FALE/UFMG, 2012.

BISOL, Leda. O ditongo na perspectiva da fonologia atual. D.E.L.T.A. São Paulo, v. 5, n. 2, 1989, p. 185-224.

BISOL, Leda. Ditongos derivados. D.E.L.T.A. São Paulo, v. 10, n. Especial, 1994, p. 123-140. 
CABREIRA, Sílvio. A monotongação dos ditongos orais decrescentes em Curitiba, Florianópolis e Porto Alegre. 1996. Dissertação (Mestrado em Letras) - Faculdade de Letras, Pontifícia Universidade Católica do Rio Grande do Sul, 1996.

CAMARA JR., Joaquim Mattoso. Para o estudo da fonêmica portuguesa. Rio de Janeiro: Padrão, 1977.

CARRAHER, Terezinha Nunes. Explorações sobre o desenvolvimento da competência em ortografia em Português. Psicologia: Teoria e Pesquisa, 13, p. 269-285, 1990.

CLEMENTS, George N.; HUME, Elizabeth V. The Internal Organization of speech sounds. In: GOLDSMITH, John (Org.). The Handbook of Phonological Theory. Londres: Black-well, 1995. p. 245-301.

CUNHA, Ana Paula Nobre da. As segmentações não-convencionais da escrita inicial: uma discussão sobre o ritmo linguístico do português brasileiro e europeu. 2010. Tese (Doutorado em Educação) - Universidade Federal de Pelotas, Pelotas, 2010.

CUNHA, Ana Paula Nobre da. A hipo e a hipersegmentação nos dados de aquisição da escrita: um estudo sobre a influência da prosódia. 2004. Dissertação (Mestrado em Educação) - Universidade Federal de Pelotas, Pelotas, 2004.

HORA, Dermeval da. \& RIBEIRO, Sílvia Renata. Monotongação de ditongos orais decrescentes: fala versus grafia. In: GORSKY, Edair Maria; COELHO, Izete Lehmkuhl (Org.). Sociolinguística e ensino: contribuições para a formação do professor de línguas. Florianópolis: Ed. da UFSC, 2006, p. 209-226.

HORA, Dermeval da. A monotongação na produção escrita: reflexo da fala. In: X Simposio Internacional em Comunicación Social, 2007, Santiago de Cuba. Actas I - X Simposio Internacional em Comunicación Social. Santiago de Cuba: Centro de Linguística Aplicada, 2007. v. 1.p. 127-131.

MENN, L; STOLEL-GAMMOM, Carol. Desenvolvimento Fonológico. In: FLETCHER, Paul; MAC WHINNEY, Brian. O compêndio da linguagem da criança. Porto alegre: Artes Médicas, 1997.

MIRANDA, Ana Ruth Moresco. A fonologia em dados de escrita inicial de crianças brasileiras. Revista Linguistica. Madrid, v. 30, p. 45-80, 2014.

MIRANDA, Ana Ruth Moresco. Reflexões sobre a fonologia e a aquisição da linguagem oral e escrita. Veredas, online, 16: 118135, 2012.

MIRANDA, Ana Ruth Moresco. Um estudo sobre o erro ortográfico. In: HEINING, Otília Lizete; FRONZA, Cátia de Azevedo. (Orgs.). Diálogos entre linguística e educação. 1 ed. Blumenau: EDIFURB, 2010, v. 1, p. 141-162.

MIRANDA, Ana Ruth Moresco. A aquisição ortográfica das vogais do português - relações com a fonologia e a morfologia. Revista Letras (Programa de Pós-Graduação em Letras da UFSM), n. 36, janeiro/junho de 2008. 
ROMBALDI, Cláudia Regina Minossi. A grafia da nasalidade por alunos de FLE: uma discussão sobre a relação Fonologia-Ortografia. 2011. Tese (Doutorado em Educação) Universidade Federal de Pelotas, 2011.

SOARES, Magda. Alfabetização: a questão dos métodos. São Paulo: Contexto, 2017.

TASCA, Maria. Interferência da língua falada na escrita das séries iniciais - o papel de fatores linguísticos e sociais. Porto Alegre: Ed. da PUCRS, 2002.

ZORZI, Jaime Luiz. Aprender a escrever: a apropriação do sistema ortográfico. Porto Alegre: Artmed, 1998.

Recebido em: 25 de fevereiro de 2019

Aceito em: 20 de dezembro de 2019

Publicado em Maio de 2020 